\title{
Sleep disturbance and treatment adherence: commentary on the study by Bosch et al. (2016)
}

\author{
Kanako Ishizuka', Toshiya Inada ${ }^{1,2}$ \\ 1Department of Psychiatry, Nagoya University Hospital, Nagoya-shi 466-8560, Japan. \\ ${ }^{2}$ Department of Psychiatry and Psychobiology, Nagoya University Graduate School of Medicine, Nagoya-shi 466-8550, Japan.
}

Correspondence to: Dr. Toshiya Inada, Department of Psychiatry and Psychobiology, Nagoya University Graduate School of Medicine, Tsurumai-cho 65, Aichi, Showa-ku, Nagoya-shi 466-8550, Japan. E-mail: toshiya.inada@gmail.com

How to cite this article: Ishizuka K, Inada T. Sleep disturbance and treatment adherence: commentary on the study by Bosch et al.
(2016). Neuroimmuno/ Neuroinflammation 2018;5:15. http://dx.doi.org/10.20517/2347-8659.2018.14

Received: 28 Mar 2018 Accepted: 28 Mar 2018 Published: 26 Apr 2018

Science Editor: Athanassios P. Kyritsis Copy Editor: Guang-Zhe Zhu Production Editor: Huan-Liang Wu

Treatment adherence is essential for optimizing healthcare outcomes, especially in individuals with schizophrenia or depression ${ }^{[1,2]}$. Previous studies identified several factors that predict treatment adherence, including psychiatric diagnoses, patients' characteristics, side-effects of psychotropic agents, symptom relief, and the patient-doctor relationship ${ }^{[3-5]}$. However, specific predisposing factors for treatment nonadherence in patients with psychiatric disorders is unknown. The present study by Bosch et al. ${ }^{[6]}$ focused on the quality of sleep as one of the factors that could help to explain treatment nonadherence in patients with schizophrenia or depression. Their findings show that in patients with schizophrenia, more severe negative symptoms and better quality of sleep was associated with better treatment adherence. By contrast, in patients with depression, symptom severity or quality of sleep was not associated with treatment adherence.

The present study is noteworthy for its uncomplicated design with the use of well-established and standardized rating scales, making it easily replicated anywhere throughout the world. In addition, the merit of the current study findings can also be easily applied to actual clinical settings because all participants are outpatients of a clinic, at which most patients with schizophrenia and depression have been treated.

However, as Bosch et al ${ }^{[6]}$ noted the study's findings must be interpreted carefully. For example, treatment adherence was measured by self-reported sleep logs. Although self-reporting is a convenient survey method, it can produce unreliable responses that are influenced by such factors as psychiatric symptoms, cognitive function, premorbid characteristics and pharmacological intervention, which may preclude

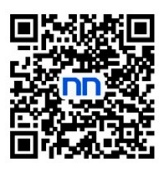


accurate measurement of "real" treatment adherence. In fact, it is unclear whether sleep disturbance, a major comorbid condition of schizophrenia and depression, directly affects treatment adherence. According to previous reviews of patients with schizophrenia, sleep disturbances are not predisposing factors for medication nonadherence ${ }^{[7,8]}$. Therefore, the study's findings might only imply that schizophrenic patients with severe negative symptoms or better quality of sleep tend to complete the sleep log form and to submit it to their physicians.

In spite of the challenges in acquiring valid measurements of treatment adherence, the study illustrates key steps that are needed for the evidence-based intervention. It gives us a better understanding of the possible difference of the reasons related to nonadherence between schizophrenia and depression observed in this study, which may elicit a clue to elucidate the possible differences of underlying mechanisms of sleep disturbance among psychiatric disorders. Studies examining factors to maintain the treatment adherence has always been extensively conducted as one of the important topics to prevent the relapse of various psychiatric disorders since effective psychopharmacological treatments were established in the 1950 . However, the relative importance of these factors contributing to treatment adherence varies depending on the psychiatric disorders. Thus, further research is needed to identify specific risk factors in treatment nonadherence for each psychiatric disorder.

\section{DECLARATIONS}

\section{Authors' contributions}

Drafted the manuscript text, developed the intellectual ideas, made the suggested revisions, and approved the final version to be published: Ishizuka K, Inada T

\section{Financial support and sponsorship}

None.

\section{Conflicts of interest}

There are no conflicts of interest.

\section{Patient consent}

Not applicable.

\section{Ethics approval}

Not applicable.

\section{Copyright}

(c) The Author(s) 2018.

\section{REFERENCES}

1. Velligan DI, Lam F, Ereshefsky L, Miller AL. Psychopharmacology: perspectives on medication adherence and atypical antipsychotic medications. Psychiatr Serv 2003;54:665-7.

2. Pampallona S, Bollini P, Tibaldi G, Kupelnick B, Munizza C. Patient adherence in the treatment of depression. Br J Psychiatr 2002;180:104-9.

3. Demyttenaere K. Compliance during treatment with antidepressants. J Affect Disord 1997;8:27-39.

4. Klein DN, Schwartz JE, Santiago NJ, Vivian D, Vocisano C, Castonguay LG, Arnow B, Blalock JA, Manber R, Markowitz JC, Riso LP, Rothbaum B, McCullough JP, Thase ME, Borian FE, Miller IW, Keller MB. Therapeutic alliance in depression treatment: controlling for prior change and patient characteristics. J Consul Clin Psychol 2003;71:997.

5. McCabe R, Bullenkamp J, Hansson L, Lauber C, Martinez-Leal R., Rössler W, Salize HJ, Svensson B, Torres-Gonzalez F, van den Brink R, Wiersma D, Priebe S. The therapeutic relationship and adherence to antipsychotic medication in schizophrenia. PLoS One 2012;7:e36080.

6. Bosch P, Waberg J, van den Noort M, Staudte H, Lim S, Egger J. Symptom severity, quality of sleep, and treatment adherence among patients suffering from schizophrenia and depression. Neuroimmunol Neuroinflammation 2016;3:109-16. 
7. Lacro JP, Dunn LB, Dolder CR, Leckband SG, Jeste DV. Prevalence of and risk factors for medication nonadherence in patients with schizophrenia: a comprehensive review of recent literature. J Clin Psychiatr 2002;63:892-909.

8. Novick D, Haro JM, Suarez D, Perez V, Dittmann RW, Haddad PM. Predictors and clinical consequences of non-adherence with antipsychotic medication in the outpatient treatment of schizophrenia. Psychiatr Res 2010;176:109-13. 